\title{
AVALIAÇÃO DO ZnO SINTETIZADO PELO MÉTODO DE PECHINI NA DEGRADAÇÃO DO CORANTE AZUL DE METILENO
}

\author{
L. A. CAVALCANTE ${ }^{1}$, L. A. POCKIFKA ${ }^{2}$, Y. K. P. G. AUM ${ }^{1}$, e Q. H. F. REBELO ${ }^{3}$ \\ ${ }^{1}$ Universidade Federal do Amazonas, Departamento de Engenharia Química \\ 2 Universidade Federal do Amazonas, Departamento de Química \\ ${ }^{3}$ Universidade Federal do Amazonas, Departamento de Engenharia de Materiais \\ E-mail para contato: luycavalcant@gmail.com
}

\begin{abstract}
RESUMO - Os corantes orgânicos constituem uma importante parcela dos poluentes descartados no meio ambiente, oriundos das indústrias têxteis, de papel e impressão. O Azul de metileno é um corante orgânico, frequentemente utilizado nas indústrias têxteis, cosméticos e farmacêutica. Partículas de óxido de zinco $(\mathrm{ZnO})$ foram preparadas pelo método de Pechini e calcinadas à temperaturas de $400^{\circ} \mathrm{C}$ e $800^{\circ} \mathrm{C}$, visando a degradação do azul de metileno. As partículas foram caracterizadas pela técnica de difração de raios-X (DRX) e sua atividade na degradação do corante foi observada através de análise por espectroscopia UV/Visível. Os difratogramas obtidos mostraram que somente nas partículas obtidas à $800^{\circ} \mathrm{C}$ foi possível identificar a estrutura cristalina hexagonal do $\mathrm{ZnO}$. Contudo, as partículas obtidas à $400^{\circ} \mathrm{C}$ apresentaram melhor desempenho na remoção do corante da solução, $66,1 \%$ de eficiência de remoção, contra $30,7 \%$ à $800^{\circ} \mathrm{C}$. Esses resultados indicam que a temperatura de calcinação da substância sintetizada pode estar influenciando na capacidade de degradação do azul de metileno.
\end{abstract}

\section{INTRODUÇÃO}

Os corantes oriundos de processos industriais, como fabricação de papel, indústria têxtil, galvanoplastia, produção de alimentos e cosméticos são as principais fontes de poluição da água. Esses corantes possuem estruturas aromáticas complexas e apresentam propriedades xenobióticas, características que tornam difícil a sua degradação (PARIDA et al, 2010).

$\mathrm{O}$ azul de metileno é um corante catiônico, de fórmula molecular $\mathrm{C}_{16} \mathrm{H}_{18} \mathrm{ClN}_{3} \mathrm{~S}$. Este corante apresenta diversas aplicações, sendo utilizado no tingimento de algodão, lãs e papel, tinturas temporárias para cabelos, etc (OLIVEIRA et al., 2013).

A estrutura química complexa dos corantes podem tornar os tratamentos químicos, físicos e biológicos ineficientes. Assim, a remoção por métodos eletroquímicos e fotooxidação se mostram mais eficientes, devido à degradação até a formação de $\mathrm{CO}_{2}$ e $\mathrm{H}_{2} \mathrm{O}$. Óxidos metálicos são uma classe de materiais empregados com sucesso na fotocatálise com aplicações que vão de vidros autolimpantes a processos oxidativos avançados (BÜRGER, 2011). 
Dessa forma, este trabalho tem como objetivo investigar o uso de partículas de $\mathrm{ZnO}$ na degradação do azul de metileno. Para isso, partículas de $\mathrm{ZnO}$ foram sintetizadas pelo método de Pechini, à diferentes temperaturas de calcinação, $400^{\circ} \mathrm{C}$ e $800^{\circ} \mathrm{C}$, e caracterizadas quanto a estrutura cristalina por difração de raios-X. A influência da temperatura de calcinação na estrutura do material particulado de $\mathrm{ZnO}$ e na capacidade de degradação do azul de metileno também foi analisada.

\section{MATERIAS E MÉTODOS}

\subsection{Materiais}

Os reagentes utilizados na realização dos experimentos foram o sulfato de zinco heptahidratado P.A., ácido cítrico monohidratado P.A., etileno glicol P.A, azul de metileno e Água Milli-Q. Os equipamentos utilizados neste trabalho foram: Banho Ultratermoestático micro circulador, modelo Q214M2 - QUIMIS; Mufla EDG - Equipamentos, 3P-S; Difratômetro Shimadzu DRX-7000; Espectrofotômetro UV/Vis, Thermo Scientific, ABS:100-900nm.

\subsection{Síntese das Partículas de ZnO}

A resina de óxido de zinco foi sintetizada pelo Método de Pechini (PECHINI, 1967), mostrado na Figura 1. O precursor metálico, o sal $\mathrm{ZnSO}_{4}$, foi dissolvido na solução de citrato feita com ácido cítrico (AC) e adicionando o etileno glicol (EG), para polimerização.

Figura 1 - Fluxograma das etapas de preparação de partículas de $\mathrm{ZnO}$ pelo método de Pechini

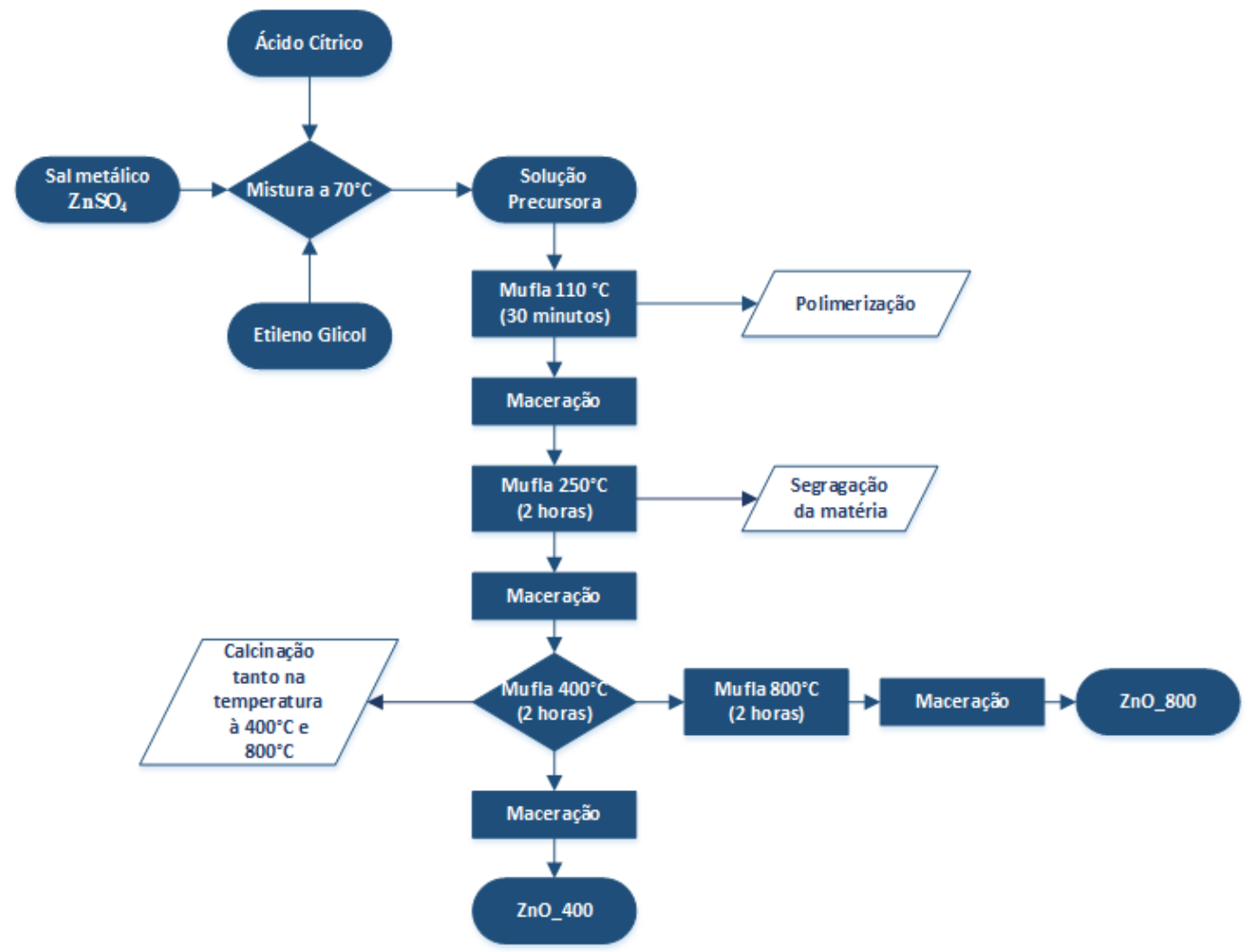


A resina foi preparada na proporção molar de 1:3:12 $\left(\mathrm{ZnSO}_{4}: \mathrm{AC}: \mathrm{EG}\right)$. Esses compostos foram misturados em um béquer e esse foi submetido à agitação em um banho termostático, a uma temperatura de $70^{\circ} \mathrm{C}$, durante $3 \mathrm{~h}$. Um gel é obtido nessa etapa e em seguida é submetido a aquecimento em três temperaturas diferentes, tais como: polimerização à $110^{\circ} \mathrm{C}$, durante 30 minutos; segregação da matéria à $250^{\circ} \mathrm{C}$, durante 2 horas; calcinação à $400^{\circ} \mathrm{C}$, durante 2 horas. Ao final de cada calcinação, a resina foi macerada em um almofariz e após a última calcinação e maceração, um pó branco foi obtido. Uma segunda amostra de resina foi preparada seguindo as mesmas etapas anteriores, contudo uma etapa a mais de calcinação foi realizada a uma temperatura de $800^{\circ} \mathrm{C}$, durante 2 horas.

\subsection{Análise Estrutural do $\mathrm{ZnO}$}

O método de difração de raios-X (DRX) foi utilizado na caracterização da microestrutura cristalina do óxido de zinco. Os dados de DRX foram coletados em um

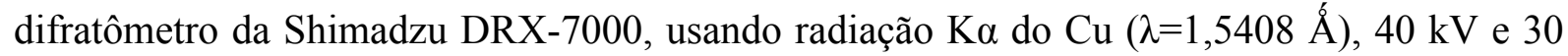
$\mathrm{mA}$. Duas amostras de $\mathrm{ZnO}$ foram analisadas, uma calcinada à temperatura de $400^{\circ} \mathrm{C}$ e a outra à temperatura de $800^{\circ} \mathrm{C}$. Cada amostra foi colocada em uma placa de silício e inserida no equipamento para a realização da leitura. $\mathrm{O}$ resultado obtido do equipamento, com o ângulo de varredura de 5 a $80^{\circ}$, apresenta o tamanho de cristalito de um material em relação as duas temperaturas de tratamento térmico das amostras.

O tamanho de cristalito para o $\mathrm{ZnO}$ foi determinado utilizando a equação de Scherrer, mostrada na Equação 1.

$$
D=\frac{0,91 \lambda}{\beta_{h k l} \cos \theta}
$$

onde $\lambda=0,154 \mathrm{~nm}$ é o comprimento de onda da radiação do equipamento $\mathrm{Cu} \mathrm{K} \alpha, \beta_{h k l}$ está relacionada com a largura da meia altura do ângulo de Bragg e $\theta$ é ângulo de difração de Bragg.

\subsection{Ensaios de Degradação do Azul de Metileno}

A degradação do azul de metileno foi analisada através da adição de $0,1 \mathrm{~g}$ de óxido de zinco, calcinado em $400^{\circ} \mathrm{C}$ e $800^{\circ} \mathrm{C}$, à uma solução de $1 \mathrm{mg} / \mathrm{L}$ do corante. O experimento foi realizado sem fornecimento de luz UV incidente, durante um tempo total de $120 \mathrm{~min}$. Amostras da mistura reacional eram colhidas a cada 10 min, filtradas e a absorbância lida em espectrofotômetro UV/Vis, em $\lambda=664 \mathrm{~nm}$. Os valores de concentração foram determinados com base na curva de calibração construída previamente, Concentração $(\mathrm{mg} / \mathrm{L})=$ 7,2186. Absorbância + 0,0937, com $\mathrm{R}^{2}=0,9979$.

\section{RESULTADOS E DISCUSSÃO}

\subsection{Caracterização do $\mathrm{ZnO}$ sintetizado}

Na Figura 2 temos os difratogramas obtidos para duas temperaturas de calcinação. Visualmente, temos que para a amostra calcinada a $400^{\circ} \mathrm{C}$ (linha verde) não foi possível 
identificar nenhuma fase, a quantidade de picos pode estar relacionada a quantidade de material orgânico presente na amostra, já para a amostra calcinada a $800^{\circ} \mathrm{C}$ (linha preta) temos picos bem definidos e alargados. Portanto, a amostra calcinada $800^{\circ} \mathrm{C}$ ficou melhor de ser caracterizada e comparada com a amostra padrão de $\mathrm{ZnO}$.

Para a amostra calcinada a $800^{\circ} \mathrm{C}$ foi possível identificar a fase do $\mathrm{ZnO}$, com estrutura cristalina hexagonal, grupo espacial P63mc (186) de acordo com a base de dados JCPDS (Cartão $\mathrm{n}^{\circ}$ 76-0704), base de comparação padrão de óxido de zinco comumente utilizada na caracterização dessa estrutura, conforme Figura 3.

Figura 3 - Difratogramas por DRX da amostra de $\mathrm{ZnO}$ à $800^{\circ} \mathrm{C}$.

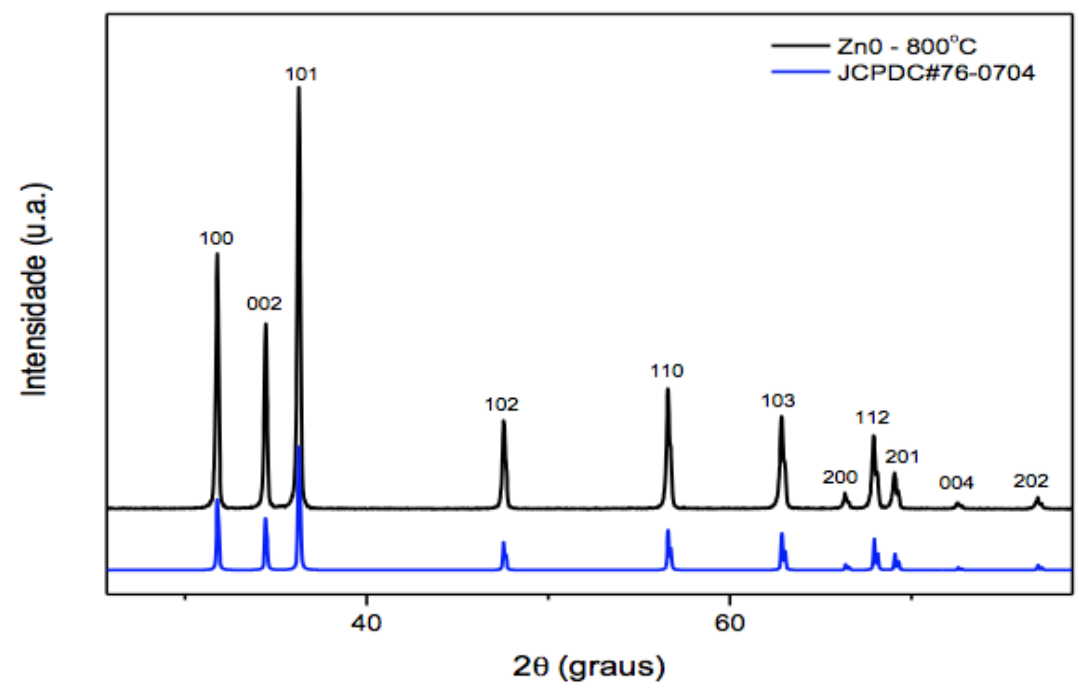

Para estimar os tamanhos de cristalito aparente para o $\mathrm{ZnO}$ foram utilizados os planos (101), (002), (101), (102), (110), (103) e (112), onde obteve-se valor de aproximadamente $37,4 \mathrm{~nm}$ conforme valores descritos na Tabela 1 . Se considerarmos apenas o pico do padrão de DRX onde a intensidade é máxima temos o tamanho de cristalino de aproximadamente $36,92 \mathrm{~nm}$, indicando que na síntese realizada houve a formação de nanopartículas.

Tabela 1 - Informações cristalográficas obtidas do padrão de DRX do $\mathrm{ZnO}$ e a relação de intensidade obtida através do cartão JCPDS\#76-0704.

\begin{tabular}{cccccc}
\hline hkl & $\begin{array}{c}2 \theta \\
\text { (graus) }\end{array}$ & $\begin{array}{c}\cos \theta \\
\text { (radianos) }\end{array}$ & (radianos) & $\mathrm{I}(\%)$ & $\begin{array}{c}\mathrm{D} \\
(\mathrm{nm})\end{array}$ \\
\hline 101 & 31,83 & 0,0167 & 0,2 & 57,0 & 41,95 \\
002 & 34,37 & 0,0166 & 0,19 & 41,5 & 44,43 \\
101 & 36,39 & 0,0165 & 0,23 & 100 & 36,92 \\
102 & 47,52 & 0,0159 & 0,26 & 21,2 & 33,89 \\
110 & 56,57 & 0,0153 & 0,3 & 30,8 & 30,53 \\
103 & 52,77 & 0,0156 & 0,35 & 26,5 & 25,66 \\
112 & 67,93 & 0,0144 & 0,2 & 22,0 & 48,65 \\
\hline \multicolumn{6}{c}{ TAMANHO MÉDIO DE CRISTALITO } \\
\hline
\end{tabular}




\subsection{Ensaios de Degradação do Azul de Metileno}

Os resultados da degradação do corante para a concentração de $1 \mathrm{mg} / \mathrm{L}$ de azul de metileno, ao adicionar $0,1 \mathrm{~g}$ de $\mathrm{ZnO}$, sintetizado a $400^{\circ} \mathrm{C}\left(\mathrm{ZnO}_{400}\right)$ e outro a $800^{\circ} \mathrm{C}\left(\mathrm{ZnO}_{800}\right)$ estão mostrados na forma de gráficos, nas Figuras 4 e 5, respectivamente.

Figura 4 - Degradação do azul de metileno ao longo do tempo com o $\mathrm{ZnO}_{400}$.

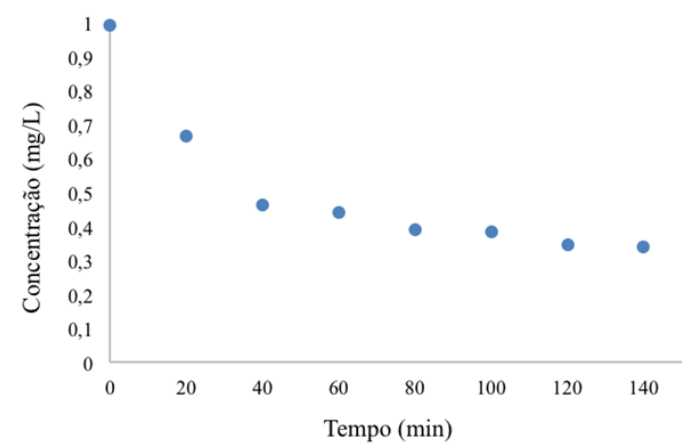

Figura 5 - Degradação do azul de metileno ao longo do tempo com o $\mathrm{ZnO}_{800}$

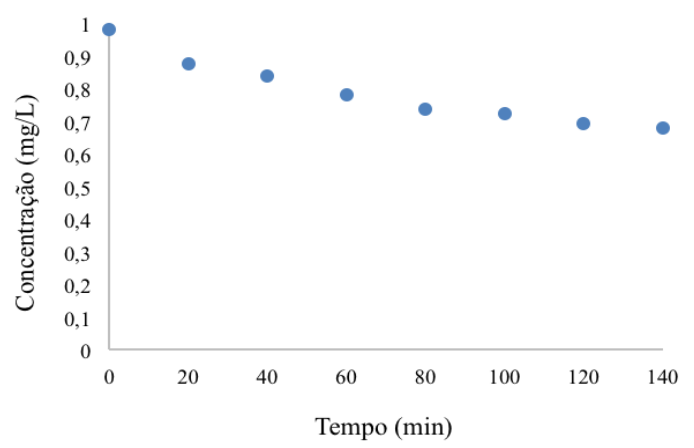

De acordo com a Figura 4, a descoloração da solução se deu rapidamente ao adicionar $\mathrm{ZnO}_{400}$. Já nos primeiros 20 min de experimento a concentração caiu para, aproximadamente, $0,66 \mathrm{mg} / \mathrm{L}$. O perfil da concentração decai com tempo, alcançando uma concentração estável de $0,34 \mathrm{mg} / \mathrm{L}$ após $140 \mathrm{~min}$. A Figura 5 mostra o efeito da adição de $\mathrm{ZnO}_{800}$ na concentração do corante na solução. Também foi possível observar o efeito dessas partículas na remoção do corante, diminuindo a concentração, com $0,68 \mathrm{mg} / \mathrm{L}$ após $140 \mathrm{~min}$. As Figuras 6 e 7 mostram os resultados obtidos em termos de eficiência de remoção do azul de metileno.

Figura 6 - Eficiência de remoção do corante utilizando o $\mathrm{ZnO}_{400}$.

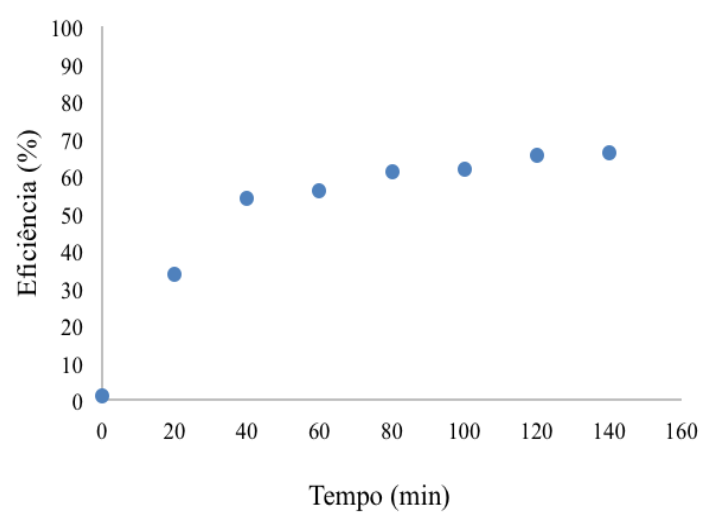

Figura 7 - Eficiência de remoção do corante utilizando o $\mathrm{ZnO}_{800}$.

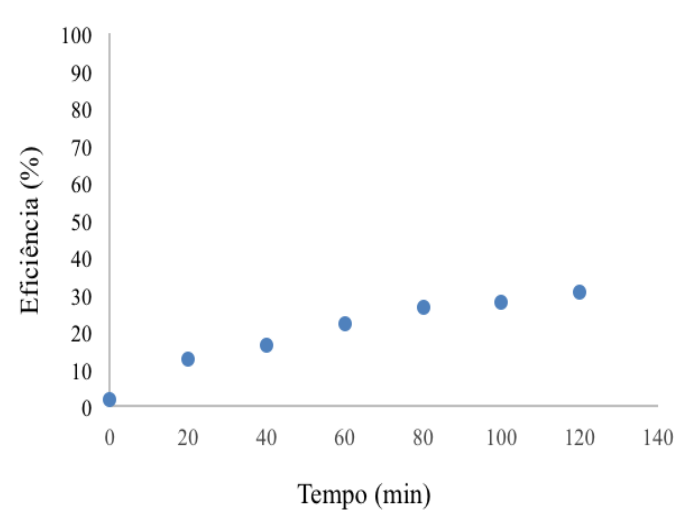

Observando as Figuras 6 e 7, a eficiência máxima alcançada pelo $\mathrm{ZnO}_{400}$ foi de $66,1 \%$ contra 30,7\% $\mathrm{ZnO}_{800}$. Após um tempo de $20 \mathrm{~min}$, a eficiência de remoção do azul de metileno pelo $\mathrm{ZnO}_{400}, 33,6 \%$, já se mostrou superior à máxima alcançada pelo $\mathrm{ZnO}_{800}$. 


\section{CONCLUSÃO}

Os resultados obtidos durante o desenvolvimento deste estudo mostraram que foi possível a obtenção de nanopartículas de $\mathrm{ZnO}$, sintetizadas pelo método de Pechini. Isso pôde ser observado pelo difratograma utilizando a técnica de DRX. Somente na amostra ZnO800 foi possível identificar a estrutura cristalina hexagonal, característica deste composto para utilização na fotodegradação. Como a caracterização do $\mathrm{ZnO}_{400}$ não se mostrou eficaz para caracterizar a partícula.

Os resultados de degradação do corante mostraram que ambas as amostras sintetizadas foram capazes de remover o corante da solução. Foi possível perceber no ensaio com o $\mathrm{ZnO}_{400}$ que remoção do corante foi mais eficiente quando comparado ao $\mathrm{ZnO}_{800}$, indicando que os intermediários da reação de síntese do $\mathrm{ZnO}_{400}$ podem estar atuando na remoção do corante através de um mecanismo diferente do seguido pelas partículas de $\mathrm{ZnO}_{800}$.

\section{REFERENCIAS}

BÜRGER, T. S. Desenvolvimento de filmes de $\mathrm{ZnO}$ para aplicação em fotocatálise. Dissertação de Mestrado no Programa de Pós-Graduação em Química no Instituto de Química, Universidade Federal do Rio Grande do Sul, 2011.

OLIVEIRA, S. P.; SILVA, W. L. L.; VIANA, R. R. Avaliação da capacidade de adsorção do corante azul de metileno em soluções aquosas em caulinita natural e intercalada com acetato de potássio. Cerâmica, v. 59, p. 338-344, 2013.

PARIDA, K. M.; SAHU, S.; REDDY, K. H.; SAHOO, P. C. A kinetic, thermodynamic, and mechanistic approach toward adsorption of methylene blue over water-washed manganese nodule leached residues. Industrial \& Engineering Chemistry Research, v. 50, n. 2, p. 843$848,2010$.

PECHINI, M. P.; ADAMS, N. Method of preparing lead and alcaline Earth titanates and niobates and coating method using the same to form a capacitor. US Patent no 3330697. 1967. 